\title{
Useful normal laboratory values
}

Normal blood count values from birth to 18 years

\begin{tabular}{|c|c|c|c|c|c|c|c|c|c|c|c|}
\hline Age & $\begin{array}{l}\mathrm{Hb} \\
\mathrm{g} / \mathrm{dl}\end{array}$ & $\begin{array}{l}\mathrm{RBC} \\
\times 10^{12} / \mathrm{I}\end{array}$ & HCT & $\begin{array}{l}\mathrm{MCV} \\
\mathrm{fl}\end{array}$ & $\begin{array}{l}\text { WBC } \\
\times 10^{9} / 1\end{array}$ & $\begin{array}{l}\text { Neutrophils } \\
\times 10^{9} / l\end{array}$ & $\begin{array}{l}\text { Lymphocytes } \\
\times 10^{9} / 1\end{array}$ & $\begin{array}{l}\text { Monocytes } \\
\times 10^{9} / 1\end{array}$ & $\begin{array}{l}\text { Eosinophils } \\
\times 10^{9} / 1\end{array}$ & $\begin{array}{l}\text { Basophils } \\
\times 10^{9} / 1\end{array}$ & $\begin{array}{l}\text { Platelets } \\
\times 10^{9} / 1\end{array}$ \\
\hline Birth (term infants) & $14.9-23.7$ & $3.7-6.5$ & $0.47-0.75$ & $100-125$ & $10.0-26.0$ & $2.7-14.4$ & $2.0-7.3$ & $0.00-1.9$ & $0.00-0.85$ & $0.00-0.10$ & $150-450$ \\
\hline 2 weeks & $13.4-19.8$ & $3.9-5.9$ & $0.41-0.65$ & $88-110$ & $6.0-21.0$ & $1.5-5.4$ & $2.8-9.1$ & $0.10-1.7$ & $0.00-0.85$ & $0.00-0.10$ & $170-500$ \\
\hline 2 months & $9.4-13.0$ & $3.1-4.3$ & $0.28-0.42$ & $84-98$ & $5.0-15.0$ & $0.7-4.8$ & $3.3-10.3$ & $0.40-1.2$ & $0.05-0.90$ & $0.02-0.13$ & $210-650$ \\
\hline 6 months & $10.0-13.0$ & $3.8-4.9$ & $0.30-0.38$ & $73-84$ & $6.0-17.0$ & $1.0-6.0$ & $3.3-11.5$ & $0.20-1.3$ & $0.10-1.10$ & $0.02-0.20$ & $210-560$ \\
\hline 1 year & $10.1-13.0$ & $3.9-5.1$ & $0.30-0.38$ & $70-82$ & $6.0-16.0$ & $1.0-8.0$ & $3.4-10.5$ & $0.20-0.9$ & $0.05-0.90$ & $0.02-0.13$ & $200-500$ \\
\hline $2-6$ years & $11.0-13.8$ & $3.9-5.0$ & $0.32-0.40$ & $72-87$ & $6.0-17.0$ & $1.5-8.5$ & $1.8-8.4$ & $0.15-1.3$ & $0.05-1.10$ & $0.02-0.12$ & $210-490$ \\
\hline $6-12$ years & $11.1-14.7$ & $3.9-5.2$ & $0.32-0.43$ & $76-90$ & $4.5-14.5$ & $1.5-8.0$ & $1.5-5.0$ & $0.15-1.3$ & $0.05-1.00$ & $0.02-0.12$ & $170-450$ \\
\hline \multicolumn{12}{|l|}{$12-18$ years } \\
\hline Female & $12.1-15.1$ & $4.1-5.1$ & $0.35-0.44$ & $77-94$ & $4.5-13.0$ & $1.5-6.0$ & $1.5-4.5$ & $0.15-1.3$ & $0.05-0.80$ & $0.02-0.12$ & $180-430$ \\
\hline Male & $12.1-16.6$ & $4.2-5.6$ & $0.35-0.49$ & 77- 92 & $4.5-13.0$ & $1.5-6.0$ & $1.5-4.5$ & $0.15-1.3$ & $0.05-0.80$ & $0.02-0.12$ & $180-430$ \\
\hline
\end{tabular}

Compiled from various sources. Red cell values at birth derived from skin puncture blood; most other data from venous blood.

Reproduced with permission from Elsevier Science, from Hinchliffe RF: Reference values; in Lilleyman J, Hann I, Blanchette V (eds): Pediatric Hematology, ed 2. London, Churchill Livingstone, 1999, p 2. 
Reference values for coagulation tests and inhibitors of coagulation in the healthy full-term infant during the first 6 months of life and in adults

\begin{tabular}{|c|c|c|c|c|c|c|}
\hline Tests & Day 1 (n) & Day 5 (n) & Day $30(n)$ & Day $90(n)$ & Day $180(\mathrm{n})$ & Adult (n) \\
\hline $\mathrm{PT}, \mathrm{s}$ & $13.0 \pm 1.43(61)^{1}$ & $12.4 \pm 1.46(77)^{1,2}$ & $11.8 \pm 1.25(67)^{1,2}$ & $11.9 \pm 1.15(62)^{1}$ & $12.3 \pm 0.79(47)^{1}$ & $12.4 \pm 0.78$ \\
\hline PTT, s & $42.9 \pm 5.80(61)$ & $42.6 \pm 8.62(76)$ & $40.4 \pm 7.42(67)$ & $37.1 \pm 6.52(62)^{1}$ & $35.5 \pm 3.71(47)^{1}$ & $33.5 \pm 3.44(29)$ \\
\hline Fibrinogen, g/l & $2.83 \pm 0.58(61)^{1}$ & $3.12 \pm 0.75(77)^{1}$ & $2.70 \pm 0.54(67)^{1}$ & $2.43 \pm 0.68(60)^{1,2}$ & $2.51 \pm 0.68(47)^{1,2}$ & $2.78 \pm 0.61(29)$ \\
\hline $\mathrm{FII}, \mathrm{U} / \mathrm{ml}$ & $0.48 \pm 0.11(61)$ & $0.63 \pm 0.15(76)$ & $0.68 \pm 0.17(67)$ & $0.75 \pm 0.15(62)$ & $0.88 \pm 0.14(47)$ & $1.08 \pm 0.19(29)$ \\
\hline $\mathrm{FV}, \mathrm{U} / \mathrm{ml}$ & $0.72 \pm 0.18(61)$ & $0.95 \pm 0.25(76)$ & $0.98 \pm 0.18(67)$ & $0.90 \pm 0.21(62)$ & $0.91 \pm 0.18$ & $1.06 \pm 0.22(29)$ \\
\hline FVII, U/ml & $0.66 \pm 0.19(60)$ & $0.89 \pm 0.27(75)$ & $0.90 \pm 0.24(67)$ & $0.91 \pm 0.26(62)$ & $0.87 \pm 0.20(47)$ & $1.05 \pm 0.19(29)$ \\
\hline FVIII:C, U/ml & $1.00 \pm 0.39(60)^{1,2}$ & $0.88 \pm 0.33(75)^{1,2}$ & $0.91 \pm 0.33(67)^{1,2}$ & $0.79 \pm 0.23(62)^{1,2}$ & $0.73 \pm 0.18(47)^{2}$ & $0.99 \pm 0.25(29)$ \\
\hline $\mathrm{VWF}_{\mathrm{Ag}}, \mathrm{U} / \mathrm{ml}$ & $1.53 \pm 0.67(40)^{2}$ & $1.40 \pm 0.57(43)^{\dagger}$ & $1.28 \pm 0.59(40)^{2}$ & $1.18 \pm 0.44(40)^{2}$ & $1.07 \pm 0.45(46)^{2}$ & $0.92 \pm 0.33(29)^{2}$ \\
\hline $\mathrm{FIX}, \mathrm{U} / \mathrm{ml}$ & $0.53 \pm 0.19(59)$ & $0.53 \pm 0.19(75)$ & $0.51 \pm 0.15(67)$ & $0.67 \pm 0.23(62)$ & $0.86 \pm 0.25(47)$ & $1.09 \pm 0.27(29)$ \\
\hline $\mathrm{FX}, \mathrm{U} / \mathrm{ml}$ & $0.40 \pm 0.14(60)$ & $0.49 \pm 0.15(76)$ & $0.59 \pm 0.14(67)$ & $0.71 \pm 0.18(62)$ & $0.78 \pm 0.20(47)$ & $1.06 \pm 0.23(29)$ \\
\hline $\mathrm{FXI}, \mathrm{U} / \mathrm{ml}$ & $0.38 \pm 0.14(60)$ & $0.55 \pm 0.16(74)$ & $0.53 \pm 0.13(67)$ & $0.69 \pm 0.14(62)$ & $0.86 \pm 0.24(47)$ & $0.97 \pm 0.15(29)$ \\
\hline FXII, U/ml & $0.53 \pm 0.20(60)$ & $0.47 \pm 0.18(75)$ & $0.49 \pm 0.16(67)$ & $0.67 \pm 0.21(62)$ & $0.77 \pm 0.19(47)$ & $1.08 \pm 0.28(29)$ \\
\hline FXIIIa, U/ml & $0.79 \pm 0.26(44)$ & $0.94 \pm 0.25(49)^{1}$ & $0.93 \pm 0.27(44)^{1}$ & $1.04 \pm 0.34(44)^{1}$ & $1.04 \pm 0.29(41)^{1}$ & $1.05 \pm 0.25(29)$ \\
\hline $\mathrm{FXIIIb}, \mathrm{U} / \mathrm{ml}$ & $0.76 \pm 0.23(44)$ & $1.06 \pm 0.37(47)^{1}$ & $1.11 \pm 0.36(45)^{1}$ & $1.16 \pm 0.34(44)^{1}$ & $1.10 \pm 0.30(41)^{1}$ & $0.97 \pm 0.20(29)$ \\
\hline Plasminogen CTA, U/ml & $1.95 \pm 0.35(44)$ & $2.17 \pm 0.38(60)$ & $1.98 \pm 0.36(52)$ & $2.48 \pm 0.37(44)$ & $3.01 \pm 0.40(47)$ & $3.36 \pm 0.44(29)$ \\
\hline AT & $0.63 \pm 0.12(58)$ & $0.67 \pm 0.13(74)$ & $0.78 \pm 0.15(66)$ & $0.97 \pm 0.12(60)^{1}$ & $1.04 \pm 0.10(56)^{1}$ & $1.05 \pm 0.13(28)$ \\
\hline $\mathrm{HCll}$ & $0.43 \pm 0.25(56)$ & $0.48 \pm 0.24(72)$ & $0.47 \pm 0.20(58)$ & $0.72 \pm 0.37(58)$ & $1.20 \pm 0.35(55)$ & $0.96 \pm 0.15(29)$ \\
\hline Protein C & $0.35 \pm 0.09(41)$ & $0.42 \pm 0.11(44)$ & $0.43 \pm 0.11(43)$ & $0.54 \pm 0.13(44)$ & $0.59 \pm 0.11(52)$ & $0.96 \pm 0.16(28)$ \\
\hline Protein S & $0.36 \pm 0.12(40)$ & $0.50 \pm 0.14(48)$ & $0.63 \pm 0.15(41)$ & $0.86 \pm 0.16(46)^{1}$ & $0.87 \pm 0.16(49)^{1}$ & $0.92 \pm 0.16(29)$ \\
\hline
\end{tabular}

NOTE: All factors except fibrinogen and plasminogen are expressed as units per milliliter where pooled plasma contains $1.0 \mathrm{U} / \mathrm{ml}$. Plasminogen units are those recommended by the Committee on Thrombolytic Agents (CTA). All values are expressed as mean \pm 1 SD.

${ }^{1}$ Values that do not differ statistically from the adult values.

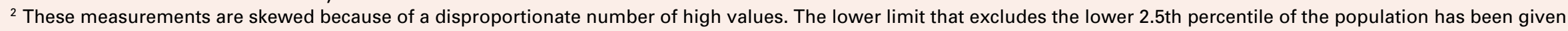
in the respective figures. The lower limit for factor VIII was $0.50 \mathrm{U} / \mathrm{ml}$ at all time points for the infant.

Modified with permission from Andrew M, Paes B, Milner R, Johnston M, Mitchell L, Tollefsen DM, Powers P: Development of the human coagulation system in the full-term infant. Blood 1987;70:165-172. 